\title{
Endoscopic retrieval of a proximally migrated bili- ary plastic stent using a guidewire loop technique
}

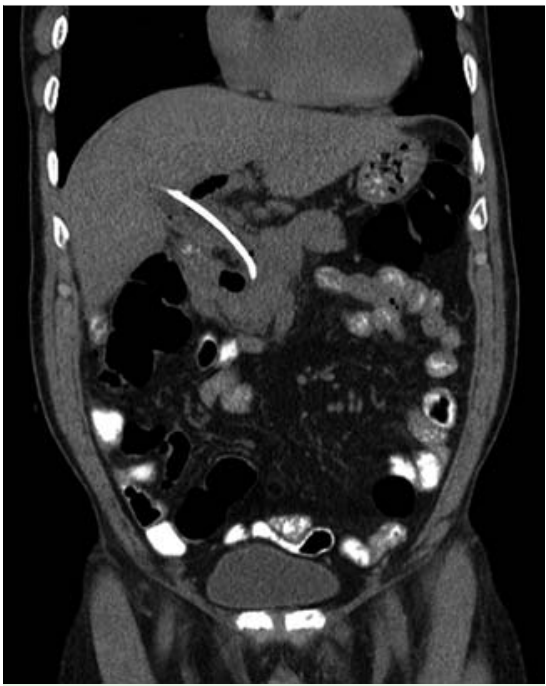

Fig. 1 Abdominal computed tomography with enhancement revealing the biliary stent proximally migrated into the common bile duct.

Endoscopic biliary stent placement is a well-established technique for various indications including biliary drainage. However, it has been shown that approximately $5 \%$ of plastic stents placed in the biliary tract migrate proximally [1]. Endoscopic retrieval of proximally migrated biliary stents is technically challenging and occasionally unsuccessful. Several techniques for retrieving proximally migrated plastic stent have been reported $[2,3]$. We report a novel technique of retrieving a proximally migrated biliary stent using a guidewire loop technique.

A 65-year-old woman visited our institution because of acute cholangitis. She had undergone cholecystectomy 2 years before this admission. Physical examination revealed fever, jaundice, and mild tenderness over the right upper quadrant. Murphy's sign was negative. Laboratory studies demonstrated a white blood cell count

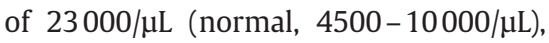
and a total bilirubin concentration of $2.7 \mathrm{mg} / \mathrm{dL}$ (normal, $0.2-1.2 \mathrm{mg} / \mathrm{dL}$ ). The patient underwent emergent endoscopic retrograde cholangiopancreatography (ERCP) for biliary decompression. The

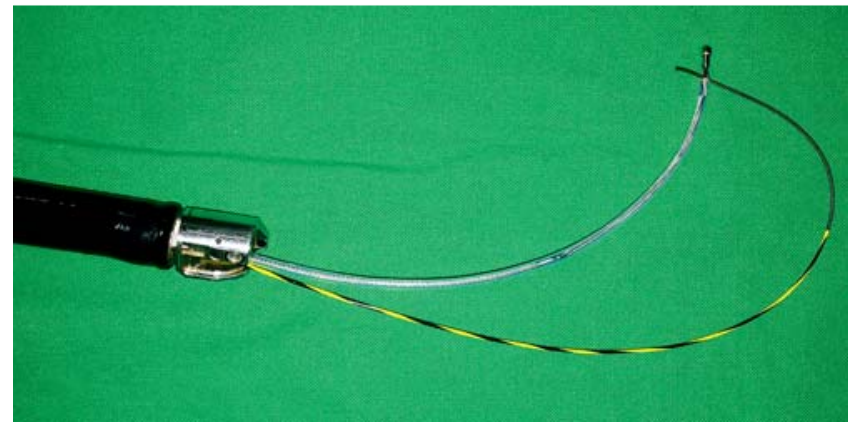

Fig. 2 A retrieval basket grasping the distal end of a guidewire was pushed through the working channel of the duodenoscope.

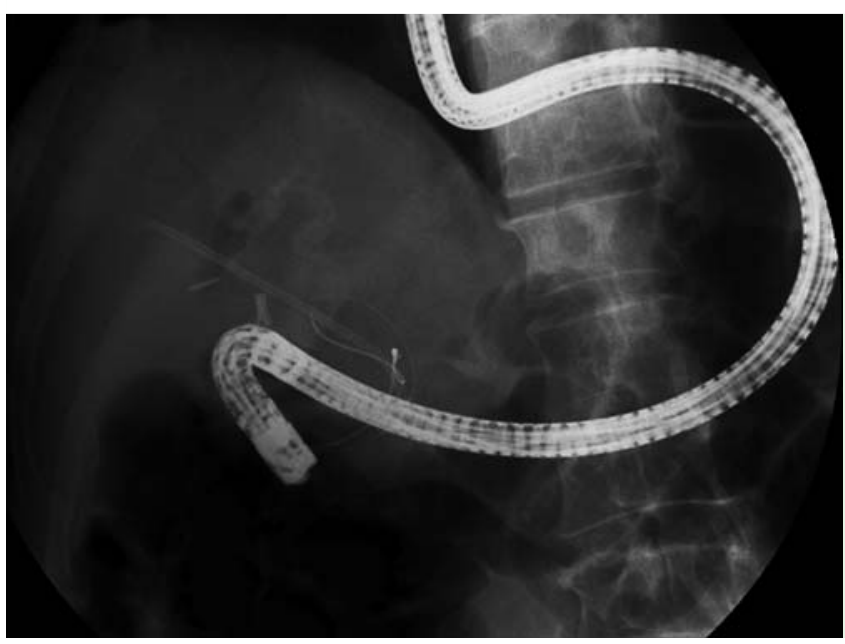

Fig. 3 Endoscopic retrograde cholangiopancreatography image showing the guidewire slightly pushed forward to form a guidewire loop and used to catch the distal side flap of the biliary stent.

ERCP image revealed common bile duct (CBD) dilatation with small filling defects in the distal CBD. A 7-cm, 7-Fr biliary stent was inserted. However, 2 months after the initial ERCP, the patient presented at the emergency department with fever and abdominal pain. Contrast-enhanced computed tomography of the abdomen revealed that the biliary stent had migrated proximally into the CBD ( $\bullet$ Fig. 1). A second ERCP was undertaken to retrieve the migrated stent. A retrieval basket (FG-23Q1; Olympus Medical Systems Corporation, Tokyo, Japan) grasping the distal end of a 0.035-inch straight guidewire (Jagwire; Boston Scientific Corporation, Natick, MA, USA) was used to retrieve the migrated stent ( $\bullet$ Fig.2). After successful biliary cannulation, the guidewire was slightly pushed forward to form a loop within the CBD ( Fig.3). By simultaneously pulling the retrieval basket and the guidewire backward, the distal side flap of the biliary stent was caught by the guidewire loop and the stent was successfully retrieved.

Endoscopy_UCTN_Code_TTT_1AR_2AZ

Competing interests: None

\section{Jyong-Hong Lee ${ }^{1}$, Sheng-Lei Yan², Chien-Hua Chen ${ }^{1}$, Yung-Hsiang Yeh², Shing-Kao Yueh ${ }^{1}$}

${ }^{1}$ Division of Gastroenterology, Department of Internal Medicine, Show-Chwan Memorial Hospital, Changhua City, Taiwan

2 Division of Gastroenterology, Department of Internal Medicine, Chang Bing Show-Chwan Memorial Hospital, Taiwan 


\section{References}

1 Johanson JF, Schmalz MJ, Geenen JE. Incidence and risk factors for biliary and pancreatic stent migration. Gastrointest Endosc 1992; 38: $341-346$

2 Chaurasia OP, Rauws EA, Fockens $P$ et al. Endoscopic techniques for retrieval of proximally migrated biliary stents: the Amsterdam experience. Gastrointest Endosc 1999; 50: $780-785$

3 Okabe Y, Tsuruta O, Kaji $R$ et al. Endoscopic retrieval of migrated plastic stent into bile duct or pancreatic pseudocyst. Dig Endosc 2009; 21: $1-7$
Bibliography

DOI http://dx.doi.org/

10.1055/s-0034-1365378

Endoscopy 2014; 46: E232-E233

(c) Georg Thieme Verlag KG

Stuttgart · New York

ISSN 0013-726X
Corresponding author

Sheng Lei Yan, MD, PhD

Division of Gastroenterology

Department of Internal Medicine

Chang Bing Show-Chwan Memorial Hospital

No. 6, Lugong Rd.

Lugang Township

Changhua County 505

Taiwan

Fax: +886-4-7073226

yslcsmc@yahoo.com 